\title{
Effects of Subchronic Exposure to Cadmium and Diazinon on Testis and Epididymis in Rats
}

\author{
Maria Adamkovicova, ${ }^{1}$ Robert Toman, ${ }^{2}$ Michal Cabaj, ${ }^{2}$ Peter Massanyi, ${ }^{3}$ \\ Monika Martiniakova, ${ }^{4}$ Radoslav Omelka, ${ }^{1}$ Vladimira Krajcovicova, ${ }^{1}$ and Hana Duranova ${ }^{4}$ \\ ${ }^{1}$ Department of Botany and Genetics, Constantine the Philosopher University, Nitra 949 74, Slovakia \\ ${ }^{2}$ Department of Veterinary Disciplines, Slovak University of Agriculture, Nitra 949 76, Slovakia \\ ${ }^{3}$ Department of Animal Physiology, Slovak University of Agriculture, Nitra 949 76, Slovakia \\ ${ }^{4}$ Department of Zoology and Anthropology, Constantine the Philosopher University, Nitra 949 74, Slovakia
}

Correspondence should be addressed to Maria Adamkovicova; madamkovicova@ukf.sk

Received 31 July 2014; Revised 16 October 2014; Accepted 4 November 2014; Published 7 December 2014

Academic Editor: Eduardo A. de Almeida

Copyright (C) 2014 Maria Adamkovicova et al. This is an open access article distributed under the Creative Commons Attribution License, which permits unrestricted use, distribution, and reproduction in any medium, provided the original work is properly cited.

\begin{abstract}
The present study aimed to elucidate the structural changes in testis and epididymis of adult rats following subchronic peroral administration of cadmium at $30 \mathrm{mg} / \mathrm{L}$, diazinon at $40 \mathrm{mg} / \mathrm{L}$, cadmium at $30 \mathrm{mg} / \mathrm{L}$, and diazinon at $40 \mathrm{mg} / \mathrm{L}$, respectively. At the end of 90-day experiment, the samples of the testes and epididymis were assayed by qualitative and quantitative histological methods. The testis and epididymis weights increased following exposure to cadmium and simultaneous exposure to cadmium and diazinon. Testicular damage following cadmium and diazinon coexposure was significantly less expressive than in groups with individual administration of these compounds. Cadmium caused a significant thickening of seminiferous epithelium, cellular degeneration, and necrosis. Desquamation of immature germ cells resulted in a significant increase of intraepithelial spaces and reduced tubule volume in all experimental groups. Vascular dilation and congestion were detected in the interstitial tissue. The changes in epididymal histology in the group exposed to cadmium and group exposed simultaneously included a reduction of epithelium, necrotic epithelial cells, vasoconstriction, and interstitial edema together with mononuclear cell infiltration. Results did not indicate a synergistic or any additional effect from the simultaneous administration of both toxicants. Further research is needed to determine the significance and the mechanism of the adverse effects.
\end{abstract}

\section{Introduction}

The ability of chemical pollutants to affect reproductive health has garnered significant attention in recent decades and is further compounded by the accumulation of endocrine disruptive chemicals in the environment $[1,2]$. Chemicals that disrupt normal endocrine function may interfere with the hormonal pathways responsible for the control of reproduction [3] triggering morphological and functional abnormalities $[4,5]$.

Cadmium is a ubiquitous environmental contaminant arising primarily from electroplating, plastics manufacturing, mining, paint pigments, alloy preparation, and batteries. Food is the most important source of cadmium in the nonsmoking, nonoccupationally exposed population [6]. Cadmium can produce both carcinogenic and noncarcinogenic effects on various organs including the lung, liver, kidney, bone, and vascular system [7]. At the cellular level, cadmium induces oxidative stress, cell proliferation, and apoptosis $[8$, 9]. Cadmium is a known endocrine disruptor and reproductive toxicant $[10,11]$ which affects male fertility through altered hypothalamic-pituitary-testicular axis function [12] and/or through direct gonadotoxic and spermiotoxic effects [13]. The disruption of junctional structures within the bloodtestis $[14,15]$ and blood-epididymis barrier $[16,17]$ results in impaired spermatogenesis and sperm maturation processes associated with infertility [18].

The organophosphate insecticide diazinon is commonly used in agriculture and households to control pest insects in soil, plants, fruit, and vegetable crops [19]. Diazinon acts on the nervous system through the inhibition of the 
acetylcholinesterase activity at the synapses and neuromuscular junctions and is manifested by overstimulation of acetylcholine receptors and impeded neurotransmission [20]. The ubiquitous distribution of both nicotinic and muscarinic cholinergic receptors together with induction of oxidative stress in various tissues [21] may have genotoxic, immunotoxic, nephrotoxic, hepatotoxic, and cardiotoxic effects [22]. Diazinon suppresses reproductive function with endogenous hormonal disruption $[5,23]$ inducing histopathological alterations in testes and spermatogenic disturbances [2426]. Exposure to diazinon negatively affects sperm motility and DNA integrity, which may contribute to reduced semen quality and concomitant decreases in fertility [27-29].

Humans are exposed to mixtures of chemicals which can interact. The most common approach to describe the combined action of the components in the mixture is to perform experimental studies comparing the effects of the mixture to the effects of the individual compounds [30, 31]. Therefore, the present study was aimed at identifying the possible interactions among cadmium and diazinon on testis and epididymis following subchronic peroral administration to rats because of their possible occurrence in the food chain.

\section{Material and Methods}

2.1. Chemicals. Cadmium in the form of cadmium chloride dehydrate compound $\left(\mathrm{CdCl}_{2} \cdot 2 \mathrm{H}_{2} \mathrm{O}\right)$, with purity $96 \%$, was purchased from Reachem, Slovak Republic. Diazinon PESTANAL, analytical standard $\left(\mathrm{C}_{12} \mathrm{H}_{21} \mathrm{~N}_{2} \mathrm{O}_{3} \mathrm{PS}\right)$, with purity 99\%, was obtained from Sigma-Aldrich Laborchemikalien GmbH, Germany.

2.2. Animals. The male Wistar rats were individually housed in plastic cages in an environment maintained at $20-24^{\circ} \mathrm{C}$, $55 \pm 10 \%$ humidity, and $12 / 12 \mathrm{~h}$ cycle of light and darkness with access to food (feed mixture M3, Machal, Czech Republic) and drinking water ad libitum. All experiments were conducted in accordance with standard guide for the care and use of laboratory animals in an accredited laboratory (SK PC 50004, SUA Nitra).

2.3. Experimental Design. The 4-week-old rats were randomly assigned into 4 groups of 10 males each. Rats in group $B$ were dosed with cadmium at $30 \mathrm{mg} / \mathrm{L}$ in drinking water for 90 days. Rats in group $\mathrm{C}$ were exposed to diazinon at $40 \mathrm{mg} / \mathrm{L}$ in drinking water for 90 days. Rats in the group $\mathrm{D}$ were given a mixture of cadmium and diazinon $(30 \mathrm{mg} / \mathrm{L}$ and $40 \mathrm{mg} / \mathrm{L}$, resp.) in drinking water for 90 days. All experimental groups were compared to a control group A with no intervention. The dose regimen and route of administration were chosen based on the experimental precedents set in the literature in order to produce a target organ toxicity arising from repeated exposure which does not induce animal mortality [32, 33]. The rats were observed daily for survival and clinical signs of toxicity. Individual body weights, food consumption, and water consumption were measured at weekly intervals.
2.4. Histological Study. Ninety days after starting the experiment, the animals were sacrificed while still under anesthesia by cervical dislocation and given a limited gross necropsy with a focus on the reproductive organs. The testes and epididymis were removed from the scrotum, freed from adherent tissues, weighed on analytical scales (JL-180, Chyo Balance Corp., Japan), and fixed in modified Davidson's solution [34]. Each portion was dehydrated in a graded series of ethanol, saturated in benzene, benzene-paraffin, embedded in paraffin wax, sectioned at $5 \mu \mathrm{m}$, and stained with hematoxylin-eosin [35]. Ten sections per organ of each animal were randomly chosen for light microscopy evaluation (Nikon Eclipse E600, Kawasaki, Kanagawa, Japan) at 200x magnification to detect qualitative histological changes produced by cadmium and diazinon.

2.5. Morphometric Analysis. Morphometric methods [16, 36] were used to quantify the structural parameters of individual tissue in ten fields per section based on computerized techniques with PC morphometric software M.I.S. QuickPhoto associated with light microscope Olympus AX 70 Provis (Olympus, Tokyo, Japan) at 400x magnification. The following measurements were performed in testis tissue: relative volume and surface area of seminiferous epithelium, intraepithelial spaces, tubule lumen, blood vessels, interstitium, tubule surface area, and tubule diameter. The following measurements were performed in epididymis tissue: relative volume and surface area of tubule epithelium, tubule lumen, blood vessels, interstitium, tubule surface area, and tubule diameter.

2.6. Statistical Analysis. Data was expressed as the mean \pm standard deviation. Differences were tested for statistical significance by one-way analysis of variance (ANOVA) and post hoc Scheffe's test using SAS 9.2 Enterprise Guide 4.3 software (SAS Institute Inc., Cary, NC, USA). The significance level was set at $5 \%\left({ }^{*} P<0.05,{ }^{* *} P<0.01\right.$, and $\left.{ }^{* * *} P<0.001\right)$.

\section{Results}

3.1. Biometry and Morphometry. Weekly body masses and food intake were not significantly different among the groups (data not shown). There were also no significant differences in final body weights. The cadmium administration significantly increased the testis $(P<0.05)$ and epididymis weight $(P<$ $0.01)$. Furthermore, significant increases in weight of testes $(P<0.01)$ and epididymis $(P<0.001)$ following simultaneous exposure to cadmium and diazinon were detected. The biometric data is presented in Table 1 .

Relative volume and surface areas of testicular tissue components were calculated. Morphometric analysis demonstrated a significant reduction $(P<0.001)$ of the seminiferous epithelium in the group exposed to cadmium accompanied by a significant increase of intraepithelial empty spaces $(P<0.001)$ in all experimental groups. Tubule lumen significantly decreased in all experimental groups, exposure to cadmium $(P<0.05)$, exposure to diazinon $(P<$ 0.001 ), and simultaneous exposure to cadmium and diazinon 
TABLE 1: Biometric parameters of control and experimental rat males.

\begin{tabular}{lcccc}
\hline Parameter & Group A & Group B & Group C & Group D \\
\hline Final body weight $(\mathrm{g})$ & $405.00 \pm 52.65$ & $426.67 \pm 25.25$ & $406.00 \pm 24.70$ & $427.78 \pm 19.22$ \\
Testis weight $(\mathrm{g})$ & $1.50 \pm 0.17$ & $1.68 \pm 0.10^{*}$ & $1.36 \pm 0.24$ & $1.75 \pm 0.18^{* *}$ \\
Epididymis weight $(\mathrm{g})$ & $0.55 \pm 0.05$ & $0.65 \pm 0.07^{* *}$ & $0.55 \pm 0.10$ & $0.66 \pm 0.06^{* * *}$ \\
\hline
\end{tabular}

The data is presented as mean and standard deviation; ${ }^{*} P<0.05 ;{ }^{* *} P<0.01$; ${ }^{* * *} P<0.001$.

TABLE 2: Morphometric testicular parameters.

\begin{tabular}{lcccc}
\hline Parameter & Group A & Group B & Group C & Group D \\
\hline Seminiferous epithelium $(\%)$ & $64.82 \pm 2.90$ & $53.67 \pm 4.31^{* * *}$ & $67.73 \pm 4.81$ & $65.76 \pm 2.89$ \\
Seminiferous epithelium $\left(\mu \mathrm{m}^{2}\right)$ & $918.82 \pm 41.06$ & $760.75 \pm 61.07^{* * *}$ & $960.05 \pm 68.18$ & $932.09 \pm 41.02$ \\
Intraepithelial spaces $(\%)$ & $0.15 \pm 0.18$ & $12.79 \pm 3.93^{* * *}$ & $5.09 \pm 1.46^{* * *}$ & $2.96 \pm 2.04^{* * *}$ \\
Intraepithelial spaces $\left(\mu \mathrm{m}^{2}\right)$ & $2.17 \pm 2.57$ & $181.25 \pm 55.72^{* * *}$ & $72.11 \pm 20.63^{* * *}$ & $42.02 \pm 28.96^{* * *}$ \\
Tubule lumen $(\%)$ & $23.58 \pm 3.03$ & $19.75 \pm 4.14^{*}$ & $14.24 \pm 3.51^{* * *}$ & $18.26 \pm 4.45^{* *}$ \\
Tubule lumen $\left(\mu \mathrm{m}^{2}\right)$ & $334.29 \pm 42.91$ & $279.99 \pm 58.69^{* *}$ & $201.86 \pm 49.81^{* * *}$ & $258.79 \pm 63.02^{* *}$ \\
Interstitial tissue $(\%)$ & $10.93 \pm 2.03$ & $11.74 \pm 3.06$ & $11.77 \pm 1.70$ & $1.01 \pm 1.43$ \\
Interstitial tissue $\left(\mu \mathrm{m}^{2}\right)$ & $154.86 \pm 28.71$ & $166.46 \pm 43.37$ & $166.89 \pm 24.14$ & $170.22 \pm 20.30$ \\
Blood vessels $(\%)$ & $0.29 \pm 0.27$ & $2.05 \pm 1.36^{* * *}$ & $1.17 \pm 0.51^{* * *}$ & $1.01 \pm 0.56^{* *}$ \\
Blood vessels $\left(\mu \mathrm{m}^{2}\right)$ & $4.16 \pm 3.77$ & $29.05 \pm 19.34^{* * *}$ & $16.61 \pm 7.25^{* * *}$ & $14.38 \pm 7.96^{* *}$ \\
Tubule surface $\left(\mu \mathrm{m}^{2}\right)$ & $372.19 \pm 69.04$ & $367.87 \pm 41.14$ & $364.57 \pm 26.17$ & $360.21 \pm 32.99$ \\
Tubule diameter $\left(\mu \mathrm{m}^{2}\right)$ & $276.22 \pm 26.28$ & $281.67 \pm 19.58$ & $273.98 \pm 9.90$ & $272.55 \pm 12.41$ \\
\hline
\end{tabular}

The data is presented as mean and standard deviation; ${ }^{*} P<0.05 ;{ }^{* *} P<0.01$; ${ }^{* * *} P<0.001$.

$(P<0.01)$. The relative volume of interstitial tissue did not differ significantly between the groups. Vascular surface area and vascular volume increased significantly in the cadmium group $(P<0.001)$, the diazinon group $(P<0.001)$, and the group with combined exposure $(P<0.01)$. No alteration was detected in the surface area and diameter of the seminiferous tubule.

Volume fractions and surface areas of epididymal tissue components were calculated. Epithelium was significantly reduced in the group exposed to cadmium $(P<0.01)$ and in the group exposed simultaneously $(P<0.05)$. A significant lumen extension in the cadmium exposed group was detected $(P<0.05)$. The combined exposure group exhibited significantly widened interstitial tissue $(P<0.001)$. Subchronic cadmium and combined exposure induced significant vascular constriction $(P<0.05)$. The significantly increased tubule surface area $(P<0.05)$ corresponds with significantly distended diameter of the epididymal tubule in the group exposed to cadmium. The morphometric data is summarized in Tables 2 and 3.

3.2. Histopathology. In the control group, testes showed normal testicular architecture. Well-developed circular or elliptical seminiferous tubules were enclosed by a thick basal lamina. The tubules were lined with seminiferous epithelium with active spermatogenesis. The germ cells were organized into concentric layers in close contact with Sertoli cells. Interstitial tissue was filled with interstitial Leydig cells, small blood vessels, collagen fibres, and fibroblasts (Figure 1(a)). Cadmium subchronic exposure resulted in moderate to severe testicular degeneration and distortion accompanied by lumen contraction (Figure 1(b)). While interstitial tissues were generally unaffected, blood vessels appeared dilated and more congested. Reduced seminiferous epithelium showed desquamation of immature germ cells with vacuole formation. Nevertheless, many seminiferous tubules showed germ cell disorganization with necrotic cellular debris, and numerous tubular lumens contained a number of mature sperms. It was found in the testis of rats exposed to diazinon that most tubules did not corroborate a significant change of germinal epithelium and interstitial connective tissue (Figure 1(c1)); however, some others appeared markedly necrotic, with degeneration of epithelial cells and only remnants of the basement membrane (Figure 1(c2)). The altered seminiferous tubules showed irregular shape, disarranged epithelial layers, and lumen filled with detached germ cells. In the most severely damaged tubules, the germ cells were not detectable, and several multinucleated bodies and cells were frequently found together with large vacuoles. Rats receiving cadmium and diazinon simultaneously showed both normal (Figure 1(d1)) and damaged seminiferous tubules in testis. The damaged tubules exhibited disorganization and degeneration of seminiferous epithelium. In particular, they lacked the characteristic basal to luminal maturation of germ cells, which was induced by desquamation of cells into the tubule lumen creating the intraepithelial empty spaces (Figure 1(d2)).

The cross sections of cauda epididymis obtained from the control group revealed regular and circular tubules with a pseudostratified columnar epithelium that exhibits stereocilia. A dense collection of sperm cells in the tubular lumen was evident. Extratubular space contained blood vessels in the interstitial connective tissue. The epithelium was 
TABLE 3: Morphometric epididymal parameters.

\begin{tabular}{lcccc}
\hline Parameter & Group A & Group B & Group C & Group D \\
\hline Epididymal epithelium $(\%)$ & $21.86 \pm 2.91$ & $18.65 \pm 1.19^{* *}$ & $20.12 \pm 4.58$ & $18.75 \pm 3.32^{*}$ \\
Epididymal epithelium $\left(\mu \mathrm{m}^{2}\right)$ & $309.92 \pm 41.31$ & $264.31 \pm 16.85^{* *}$ & $285.21 \pm 64.91$ & $265.81 \pm 47.04^{*}$ \\
Tubule lumen $(\%)$ & $69.37 \pm 4.79$ & $73.74 \pm 1.61^{*}$ & $69.05 \pm 7.07$ & $67.25 \pm 4.06$ \\
Tubule lumen $\left(\mu \mathrm{m}^{2}\right)$ & $983.35 \pm 67.91$ & $1045.21 \pm 22.78^{*}$ & $978.76 \pm 100.16$ & $953.23 \pm 57.59$ \\
Interstitial tissue $(\%)$ & $8.29 \pm 2.10$ & $7.46 \pm 1.20$ & $10.37 \pm 3.17$ & $13.87 \pm 2.54^{* * *}$ \\
Interstitial tissue $\left(\mu \mathrm{m}^{2}\right)$ & $117.50 \pm 29.80$ & $105.75 \pm 17.05$ & $146.99 \pm 44.90$ & $196.62 \pm 36.07^{* * *}$ \\
Blood vessels $(\%)$ & $0.29 \pm 0.15$ & $0.16 \pm 0.11^{*}$ & $0.26 \pm 0.15$ & $0.13 \pm 0.12^{*}$ \\
Blood vessels $\left(\mu \mathrm{m}^{2}\right)$ & $4.14 \pm 2.14$ & $2.23 \pm 1.54^{*}$ & $3.70 \pm 2.16$ & $1.87 \pm 1.68^{*}$ \\
Tubule surface $\left(\mu \mathrm{m}^{2}\right)$ & $314.32 \pm 13.10$ & $335.19 \pm 23.43^{*}$ & $318.19 \pm 25.47$ & $336.05 \pm 48.01$ \\
Tubule diameter $\left(\mu \mathrm{m}^{2}\right)$ & $254.64 \pm 5.30$ & $262.87 \pm 9.18^{*}$ & $256.07 \pm 10.28$ & $262.71 \pm 19.32$ \\
\hline
\end{tabular}

The data is presented as mean and standard deviation; ${ }^{*} P<0.05 ;{ }^{* *} P<0.01 ;{ }^{* * *} P<0.001$.

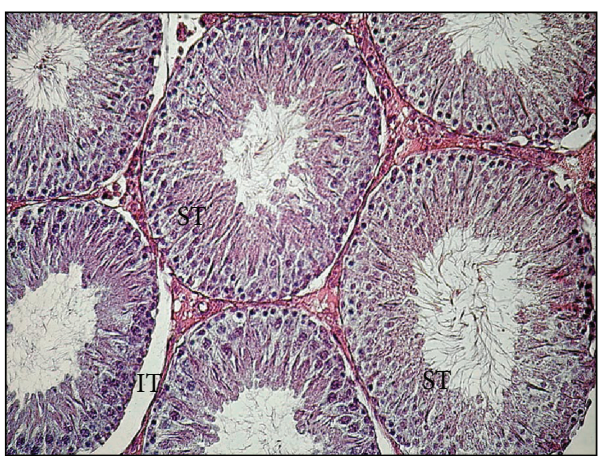

(a)

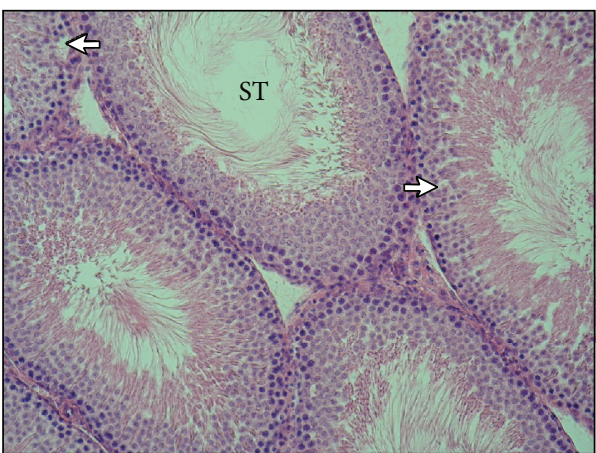

(c1)

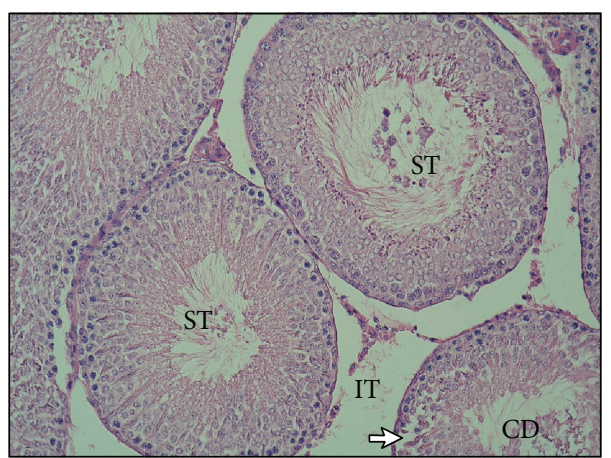

(d1)

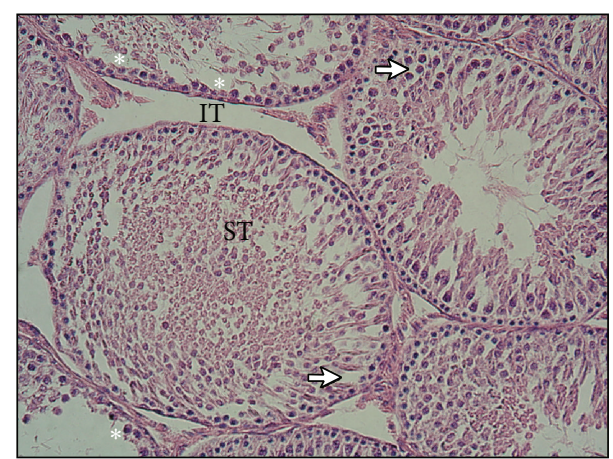

(b)

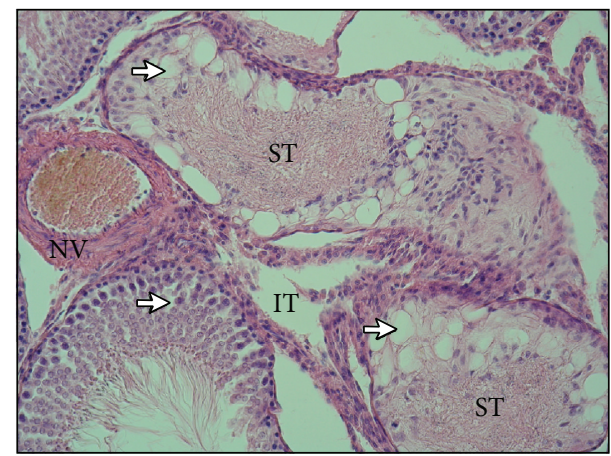

(c2)

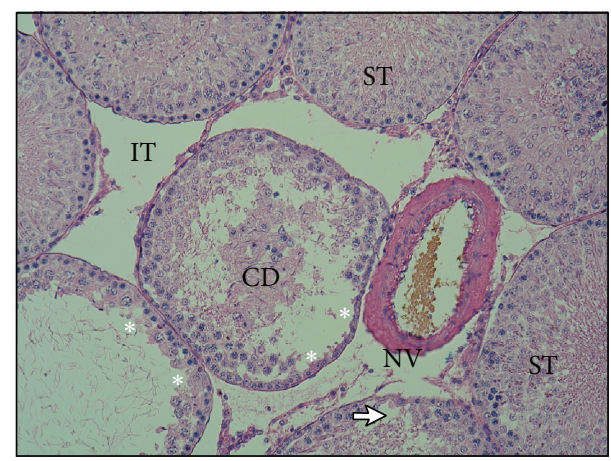

(d2)

Figure 1: Photomicrographs showing histology of testicular tissue from control group (a), group exposed to cadmium at a dose of $30 \mathrm{mg} / \mathrm{L}$ (b), group exposed to diazinon at a dose of $40 \mathrm{mg} / \mathrm{L}$ (c1, c2), and group exposed to cadmium at a dose of $30 \mathrm{mg} / \mathrm{L}$ and diazinon at a dose of $40 \mathrm{mg} / \mathrm{L}$ (d1, d2). ST: seminiferous tubules, IT: interstitial tissue, CD: cellular debris, NV: necrotizing vasculitis, arrows: intraepithelial empty spaces, and stars: seminiferous tubules lined only by Sertoli cells (hematoxylin-eosin, original magnification $\times 200$ ). 


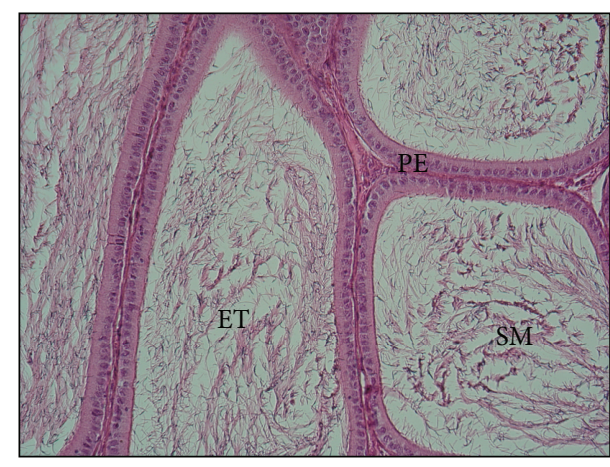

(a)

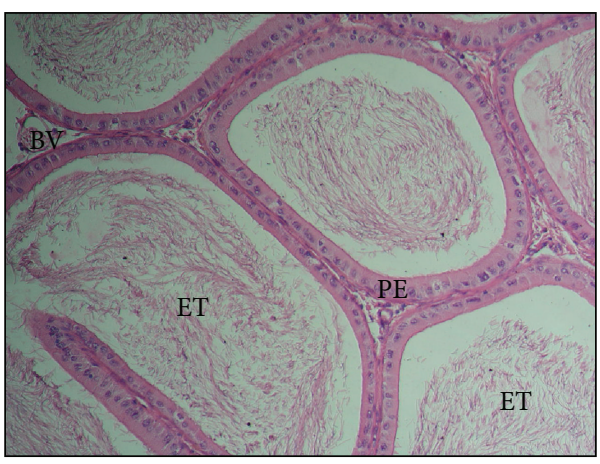

(c)

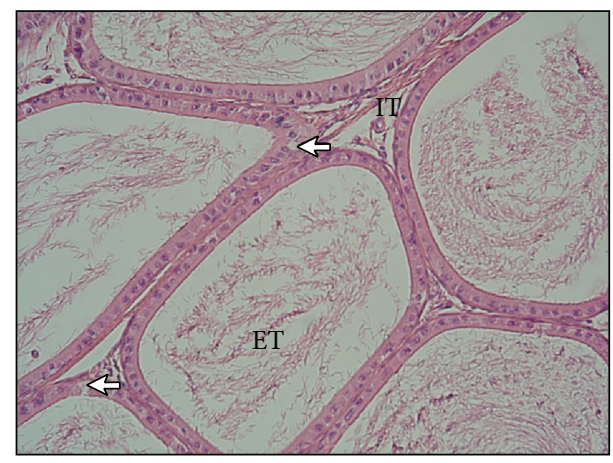

(b)

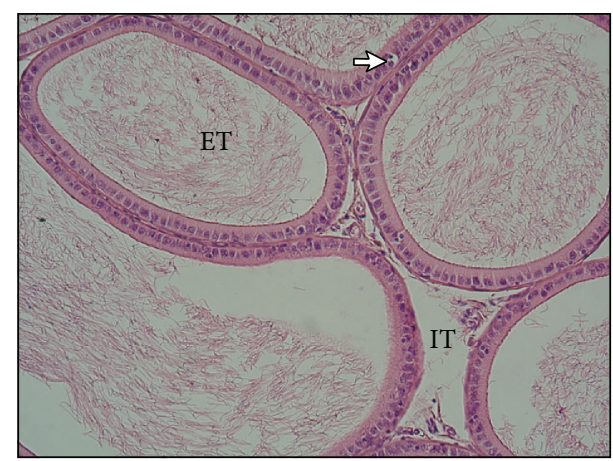

(d)

FIGURE 2: Photomicrographs showing histology of epididymal tissue from control group (a), group exposed to cadmium at a dose of $30 \mathrm{mg} / \mathrm{L}$ (b), group exposed to diazinon at a dose of $40 \mathrm{mg} / \mathrm{L}$ (c), and group exposed to cadmium at a dose of $30 \mathrm{mg} / \mathrm{L}$ and diazinon at a dose of $40 \mathrm{mg} / \mathrm{L}$ (d). ET: epididymal tubules, PE: pseudostratified columnar epithelium, IT: interstitial tissue, SM: spermatozoa, BV: blood vessels, CD: cellular debris, and arrows: intraepithelial empty spaces (hematoxylin-eosin, original magnification $\times 200$ ).

separated from the connective tissue by an intact basement membrane (Figure 2(a)). Histological analysis did not reveal differences in epididymal morphology of rats, except for the vacuole formation within pseudostratified epithelium following cadmium (Figure 2(b)) and combined cadmium and diazinon exposure in which moreover an enlargement in the interstitial space was found (Figure 2(d)). No marked alteration in epididymal structural integrity was observed in rats after diazinon exposure (Figure 2(c)).

\section{Discussion}

Histopathology is considered the most reliable parameter for the detection of toxic effects on male reproduction [37, 38]. Therefore, macroscopic, histological and morphometric examination was carried out to determine the degree of tissue damage produced by cadmium and diazinon.

4.1. Cadmium Effects on Testis and Epididymis. Cadmium accumulates in male reproductive organs, in both humans and animals [39]. Numerous studies have confirmed that the testis is more sensitive to cadmium than other important organs [40, 41]. Cadmium-induced testicular toxicity is caused by the interactions between complex networks [15], involving the inhibition of oxidative stress [8], which leads to an increase in germ cell apoptosis [9] and/or distortion of the blood-testis barrier with subsequent germ cell loss, testicular edema, and hemorrhage $[18,42]$. After prolonged exposure, damage inflicted by cadmium can be found at interstitial and tubular level [43]. Controversy exists regarding changes in testis weight after cadmium exposure. Some studies have reported atrophy of testis $[44,45]$ while others $[46,47]$ have reported increased testicular weight similar to the findings of the present study (Table 1). This suggests that the interstitial edema that occurred was due to fluid accumulation [37, 48]. Subchronic cadmium exposure at $30 \mathrm{mg} / \mathrm{L}$ resulted in moderate to severe testicular injury (Figure 1(b)). Regarding the tissue constituents of the testis, many irregularly outlined seminiferous tubules showed disarranged epithelial layers and necrotic cellular debris, which corroborates previous reports [43, 49]. Sloughing of cells into the lumen led to a significantly reduced percentage of the epithelial volume fraction accompanied by lumen contraction (Table 2). The formation of vacuoles in Sertoli cells and the almost complete absence of spermatozoa suggest an impairment of spermatogenesis [37]. Connective tissues were generally unaffected; nevertheless, blood vessels appeared dilated and more congested. These aforementioned observed changes agree with previous studies $[16,41]$ that demonstrated cadmiuminduced testicular necrosis occurs after ischemia $[13,50]$ preceded by the perturbing of blood-testis barrier integrity and disruption of cell-to-cell endothelial and epithelial junctions $[11,12,15]$. 
Disruption of cell junctions and the blood-epididymis barrier has been determined as the main target of cadmium toxicity in epididymis, leading to deficient sperm maturation and motility $[17,51]$. Subchronic exposure to cadmium caused epithelial thickening, and distension of tubule lumen (Table 3) together with granulomatous inflammation. Besides disruptive effects on epithelium, cadmium also induced vasoconstriction, ischemia, and edema. The edema is the direct consequence of altered hemodynamics mediated through injury to the vascular endothelium $[37,50]$. Increased epididymal weight generally indicates an excessive accumulation of interstitial fluid and may be a sensitive indicator of decreased sperm production [38]. The findings are consistent with earlier reports of cadmium mediated histological changes in the testes, epididymis, and accessory sex organs $[16,52]$. On the other hand, several experimental studies have presented the significant atrophy of the epididymis, decrease in the diameter of the lumen, and alkalization of the epididymis and vas deferens after cadmium administration $[51,53]$.

4.2. Diazinon Effects on Testis and Epididymis. No significant differences on the final body and testicular weight (Table 1), nor any gross pathological changes that could be attributed to diazinon exposure at $40 \mathrm{mg} / \mathrm{L}$, were found. This biometric data is in line with what was previously reported [54]. Histopathologically, the testicular tissue showed varying degrees of distortion. Many tubules did not corroborate a significant change of germinal epithelium and interstitial tissue (Figure $1(\mathrm{cl})$ ). The others appeared markedly necrotic, with degeneration of epithelial cells and only remnants of the basement membrane (Figure 1(c2)). Exfoliation of germ cells into the tubular lumen reflects the damage of Sertoli cells and the destruction of cell association [55]. Disrupting of tight junctions and adherent junctions between cells increased epithelial and endothelial permeability [42]. The morphometric analysis confirmed a significant increase of intraepithelial empty spaces accompanied by a markedly reduced tubule volume due to exposure to diazinon. In the most damaged tubules, the germ cells were not detectable, and several multinucleated cells were frequently seen together with large vacuoles. Analysis of testis sections revealed dilated and congested blood vessels (Table 2). In accordance with the present study, mild to severe degenerative changes in seminiferous tubules after exposure to various dose levels of chlorpyrifos were found [56]. Likewise, 2 weeks of exposure to diazinon resulted in a highly significant reduction of diameter size in the lumen in male adult bluegills [24]. Desquamation of germ cells, degeneration of Sertoli cells, appearance of vacuoles, and reduction in cell population occurred following exposure to quinalphos in sublethal doses [54]. Results reported herein support previous research into diazinon-induced changes to testis histopathology $[25,57]$ and corroborate reproductive toxicity following organophosphate exposure $[58,59]$. Diazinon induces the production of oxidative stress by alteration of antioxidant enzyme activity and increasing lipid peroxidation [21]. Increased oxidative stress in the testis is associated with the suppression of Leydig cell steroidogenesis [60], disruption of spermatogenesis [29], and implications for male fertility [28].

Qualitative analysis of epididymal histology in rats exposed to diazinon showed no marked structural alterations. Compactly arranged tubules with well-organized pseudostratified epithelium and lumen filled with spermatozoa were surrounded by connective tissue without visible signs of inflammation. Absence of any significant effects after 90 days may be due to the recovery from the toxicity of diazinon [61]. Comparatively, exposure of rats to dichlorvos and diazinon for 9 weeks did not change the testis, epididymis weight, and testicular structure but the histopathological alterations were observed in the epithelial cells in epididymis, in which increased cytoplasmic vacuolation and nuclear shrinkage were found [62]. In addition, epididymis weight showed no significant change in male rats exposed to chlorpyrifos; nevertheless the epididymal tubules showed increased interstitial spaces with loss of sperm [55]. On the contrary, testis, epididymis, and prostate weight decreased significantly after exposure to diazinon for 4 weeks [25]. Malathion administration also reduced epididymal weight [63], whereas increased weight of epididymis and cellular necrosis, nuclear pyknosis, and a deleterious effect on the structural integrity following methyl parathion exposure were observed $[61,64]$.

\subsection{Combined Cadmium and Diazinon Effects on Testis and} Epididymis. The testicular tissue was not uniformly affected following simultaneous exposure to cadmium and diazinon. While some tubules showed developing sperm (Figure 1(d1)), others exhibited disorganization and degeneration of seminiferous epithelium, lacking the characteristic basal to luminal maturation of germ cells (Figure $1(\mathrm{~d} 2)$ ). The progressive damage was represented by seminiferous tubules devoid of germ cells and lined by Sertoli cells only [37, 41]. The weight of testes, accessory sex organs, and epididymides are the primary indicators of a possible alteration in androgen status [47]. Significantly increased testis weight after combined peroral exposure (Table 1) may reflect increased interstitial fluid and suggests injury to vascular endothelium [38]. Disruption of tight junctions perturbs endothelial barrier function and led to hemorrhaging and edema $[15,50]$. Cadmium and diazinon administration caused a notable loss of spermatogenic elements. Degenerated epithelial cells were sloughed into the lumen of most seminiferous tubules. Detected desquamation of germ cells was reflected by significant vacuolisation and lumen contraction (Table 2) followed by maturation depletion $[37,54]$. Furthermore, congestion and dilatation of interstitial blood vessels together with necrotizing vasculitis were identified [65]; however, observed structural alterations in testicular tissue were less expressive than after exposure to either cadmium or diazinon. The combined action of cadmium and diazinon was different from estimates based on the addition of individual responses [30]. Similarly, the coexposure to cadmium and nickel did not have a synergistic effect on testicular disturbances. Combined administration produced fewer pathological alterations than that of cadmium alone [66]. The results of the present study are similar 
to previous ones [67], in which a reduced effect of cadmium in combination with diazinon on bone microstructure was observed. Cadmium can affect the acetylcholinesterase enzymatic activity in a dose and duration dependent manner [68]. It was found that the activity of acetylcholinesterase decreased in short term [44] and increased after long term exposure to cadmium [69]. Therefore, it is possible that activation of acetylcholinesterase followed after prolonged cadmium administration because of similarity to calcium, which increases enzymatic activity [70]. In the approach used in this study, a possible mechanism of action of combined exposure to cadmium and diazinon was not modeled, but rather we assumed that the reduced toxicity was due to competitive interactions among chemicals [71].

Histological examination did not reveal differences in epididymal morphology of rats, except the cytoplasmatic vacuolisation within epithelium following simultaneous exposure [37, 38]. Nevertheless, the morphometric analysis revealed increased epididymis weight and epithelial thickening accompanied by widening of the interstitial space (Table 3). Similarly, the dose-dependent epididymal toxicity induced by dichlorvos, dimethoate, and malathion mixture was associated with alterations on epididymis weight, structure, and function [72]. Reduction in capillary size confirms that cadmium-induced testicular and epididymal pathophysiology is mediated by perturbing the vascular system [50]. Any structural alteration may adversely affect function of the epididymal epithelium, which could impact sperm maturation [17]. Heavy metal and pesticide exposure are potential risk factors for adverse reproductive health outcomes, including poor semen quality $[1,3,73]$.

\section{Conclusion}

The aim of the present study was to assess the impact of cadmium and diazinon on the rat testis and epididymis by using various qualitative and quantitative histological methods. Effects on the testis included vascular disruption, interstitial edema and hemorrhage, germ cell loss, cellular degeneration, and necrosis with epithelial vacuolisation. However, observed degenerative changes after simultaneous exposure were significantly less expressive as compared to exposure to the individual compounds. Epithelial thickening, necrotic epithelial cells, vasoconstriction, interstitial edema, and mononuclear cell infiltration were most detectable in epididymis following exposure to cadmium either alone or in combination. In summary, cadmium and diazinon induced significant structural alterations in testicular and epididymal tissue which may affect male reproduction. The underlying molecular mechanism of the interaction of cadmium with diazinon should be explored in future studies.

\section{Conflict of Interests}

The authors declare that there is no conflict of interests regarding the publication of this paper.

\section{Acknowledgments}

This research was funded by the Grants KEGA 025UKF4/2012 and KEGA 035UKF-4/2013. This work was supported by European Community under Project no. 26220220180: Building Research Centre "AgroBioTech."

\section{References}

[1] S. Kumar, "Occupational exposure associated with reproductive dysfunction," Journal of Occupational Health, vol. 46, no. 1, pp. $1-19,2004$.

[2] B. H. Yeung, H. T. Wan, A. Y. Law, and C. K. Wong, "Endocrine disrupting chemicals: multiple effects on testicular signaling and spermatogenesis," Spermatogenesis, vol. 1, no. 3, pp. 231-239, 2011.

[3] E. Diamanti-Kandarakis, J.-P. Bourguignon, L. C. Giudice et al., "Endocrine-disrupting chemicals: an endocrine society scientific statement," Endocrine Reviews, vol. 30, no. 4, pp. 293342, 2009.

[4] A. Mantovani and F. Maranghi, "Risk assessment of chemicals potentially affecting male fertility," Contraception, vol. 72, no. 4, pp. 308-313, 2005.

[5] S. C. Sikka and R. Wang, "Endocrine disruptors and estrogenic effects on male reproductive axis," Asian Journal of Andrology, vol. 10, no. 1, pp. 134-145, 2008.

[6] L. Järup, "Hazards of heavy metal contamination," British Medical Bulletin, vol. 68, pp. 167-182, 2003.

[7] M. P. Waalkes, "Cadmium carcinogenesis," Mutation Research, vol. 533, no. 1-2, pp. 107-120, 2003.

[8] K. Tremellen, "Oxidative stress and male infertility-a clinical perspective," Human Reproduction Update, vol. 14, no. 3, pp. 243-258, 2008.

[9] T. T. Turner and J. J. Lysiak, "Oxidative stress: a common factor in testicular dysfunction," Journal of Andrology, vol. 29, no. 5, pp. 488-498, 2008.

[10] M. C. Henson and P. J. Chedrese, "Endocrine disruption by cadmium, a common environmental toxicant with paradoxical effects on reproduction," Experimental Biology and Medicine, vol. 229, no. 5, pp. 383-392, 2004.

[11] C. Y. Cheng, E. W. P. Wong, P. P. Y. Lie et al., "Environmental toxicants and male reproductive function," Spermatogenesis, vol. 1, no. 1, pp. 2-13, 2011.

[12] A. Lafuente, "The hypothalamic-pituitary-gonadal axis is target of cadmium toxicity. An update of recent studies and potential therapeutic approaches," Food and Chemical Toxicology, vol. 59, pp. 395-404, 2013.

[13] J. Thompson and J. Bannigan, "Cadmium: toxic effects on the reproductive system and the embryo," Reproductive Toxicology, vol. 25, no. 3, pp. 304-315, 2008.

[14] C.-H. Wong, D. D. Mruk, W.-Y. Lui, and C. Y. Cheng, "Regulation of blood-testis barrier dynamics: an in vivo study," Journal of Cell Science, vol. 117, no. 5, pp. 783-798, 2004.

[15] E. R. Siu, D. D. Mruk, C. S. Porto, and C. Y. Cheng, "Cadmiuminduced testicular injury," Toxicology and Applied Pharmacology, vol. 238, no. 3, pp. 240-249, 2009.

[16] R. Toman, P. Massányi, and V. Uhrín, "Changes in the testis and epididymis of rabbits after an intraperitoneal and peroral administration of cadmium," Trace Elements and Electrolytes, vol. 19, no. 3, pp. 114-117, 2002. 
[17] E. Dubé and D. G. Cyr, "The blood-epididymis barrier and human male fertility," Advances in Experimental Medicine and Biology, vol. 763, pp. 218-236, 2013.

[18] C. Yan Cheng and D. D. Mruk, "The blood-testis barrier and its implications for male contraception," Pharmacological Reviews, vol. 64, no. 1, pp. 16-64, 2012.

[19] S. Ş. Köprücü, K. Köprücü, M. Ş. Ural, Ü. Ispir, and M. Pala, "Acute toxicity of organophosphorous pesticide diazinon and its effects on behavior and some hematological parameters of fingerling European catfish (Silurus glanis L.)," Pesticide Biochemistry and Physiology, vol. 86, no. 2, pp. 99-105, 2006.

[20] T. C. Kwong, "Organophosphate pesticides: biochemistry and clinical toxicology," Therapeutic Drug Monitoring, vol. 24, no. 1, pp. 144-149, 2002.

[21] R. Sutcu, I. Altuntas, B. Buyukvanli et al., "The effects of diazinon on lipid peroxidation and antioxidant enzymes in rat erythrocytes: role of vitamins $\mathrm{E}$ and C," Toxicology and Industrial Health, vol. 23, no. 1, pp. 13-17, 2007.

[22] M. A. H. Yehia, S. G. El-Banna, and A. B. Okab, "Diazinon toxicity affects histophysiological and biochemical parameters in rabbits," Experimental and Toxicologic Pathology, vol. 59, no. 3-4, pp. 215-225, 2007.

[23] L. B. Maxwell and H. M. Dutta, "Diazinon-induced endocrine disruption in bluegill sunfish, Lepomis macrochirus," Ecotoxicology and Environmental Safety, vol. 60, no. 1, pp. 21-27, 2005.

[24] H. M. Dutta and H. J. M. Meijer, "Sublethal effects of diazinon on the structure of the testis of bluegill, Lepomis macrochirus: a microscopic analysis," Environmental Pollution, vol. 125, no. 3, pp. 355-360, 2003.

[25] R. H. ElMazoudy and A. A. Attia, "Endocrine-disrupting and cytotoxic potential of anticholinesterase insecticide, diazinon in reproductive toxicity of male mice," Journal of Hazardous Materials, vol. 209-210, pp. 111-120, 2012.

[26] C. T. Leong, U. J. A. D’Souza, M. Iqbal, and Z. A. Mustapha, "Lipid peroxidation and decline in antioxidant status as one of the toxicity measures of diazinon in the testis," Redox Report, vol. 18, no. 4, pp. 155-164, 2013.

[27] S. H. Swan, R. L. Kruse, F. Liu et al., "Semen quality relation to biomarkers of pesticide exposure," Environmental Health Perspectives, vol. 111, no. 12, pp. 1478-1484, 2003.

[28] B. Piña-Guzmán, M. J. Solís-Heredia, and B. QuintanillaVega, "Diazinon alters sperm chromatin structure in mice by phosphorylating nuclear protamines," Toxicology and Applied Pharmacology, vol. 202, no. 2, pp. 189-198, 2005.

[29] L. Sarabia, I. Maurer, and E. Bustos-Obregón, "Melatonin prevents damage elicited by the organophosphorous pesticide diazinon on mouse sperm DNA," Ecotoxicology and Environmental Safety, vol. 72, no. 2, pp. 663-668, 2009.

[30] V. J. Feron and J. P. Groten, "Toxicological evaluation of chemical mixtures," Food and Chemical Toxicology, vol. 40, no. 6, pp. 825-839, 2002.

[31] I. Silins and J. Högberg, "Combined toxic exposures and human health: biomarkers of exposure and effect," International Journal of Environmental Research and Public Health, vol. 8, no. 3, pp. 629-647, 2011.

[32] Agency for Toxic Substances and Disease Registry (ATSDR), Toxicological Profile for Diazinon, U.S. Department of Health and Human Services, Public Health Service, Atlanta, Ga, USA, 2008.

[33] Agency for Toxic Substances and Disease Registry (ATSDR), Toxicological Profile for Cadmium, U.S. Department of Health and Human Services, Public Health Service, Atlanta, Ga, USA, 2012.

[34] J. R. Latendresse, A. R. Warbrittion, H. Jonassen, and D. M. Creasy, "Fixation of testes and eyes using a modified Davidson's fluid: comparison with Bouin's fluid and conventional Davidson's fluid," Toxicologic Pathology, vol. 30, no. 4, pp. 524-533, 2002.

[35] R. Toman, P. Massányi, M. Adamkovicova, N. Lukac, M. Cabaj, and M. Martiniakova, "Quantitative histological analysis of the mouse testis after the long-term administration of nickel in feed," Journal of Environmental Science and Health A Toxic/Hazardous Substances and Environmental Engineering, vol. 47, no. 9, pp. 1272-1279, 2012.

[36] E. R. Weibel, G. S. Kistler, and W. F. Scherle, "Practical stereological methods for morphometric cytology," The Journal of Cell Biology, vol. 30, no. 1, pp. 23-38, 1966.

[37] D. M. Creasy, "Pathogenesis of male reproductive toxicity," Toxicologic Pathology, vol. 29, no. 1, pp. 64-76, 2001.

[38] L. L. Lanning, D. M. Creasy, R. E. Chapin et al., "Recommended approaches for the evaluation of testicular and epididymal toxicity," Toxicologic Pathology, vol. 30, no. 4, pp. 507-520, 2002.

[39] S. Benoff, A. Jacob, and I. R. Hurley, "Male infertility and environmental exposure to lead and cadmium," Human Reproduction Update, vol. 6, no. 2, pp. 107-121, 2000.

[40] R. H. Foote, "Cadmium affects testes and semen of rabbits exposed before and after puberty," Reproductive Toxicology, vol. 13, no. 4, pp. 269-277, 1999.

[41] F. de Souza Predes, M. A. S. Diamante, and H. Dolder, "Testis response to low doses of cadmium in Wistar rats," International Journal of Experimental Pathology, vol. 91, no. 2, pp. 125-131, 2010.

[42] E. W. P. Wong and C. Y. Cheng, "Impacts of environmental toxicants on male reproductive dysfunction," Trends in Pharmacological Sciences, vol. 32, no. 5, pp. 290-299, 2011.

[43] A. Blanco, R. Moyano, J. Vivo et al., "Quantitative changes in the testicular structure in mice exposed to low doses of cadmium," Environmental Toxicology and Pharmacology, vol. 23, no. 1, pp. 96-101, 2007.

[44] F. M. El-Demerdash, M. I. Yousef, F. S. Kedwany, and H. H. Baghdadi, "Cadmium-induced changes in lipid peroxidation, blood hematology, biochemical parameters and semen quality of male rats: protective role of vitamin $\mathrm{E}$ and $\beta$-carotene," Food and Chemical Toxicology, vol. 42, no. 10, pp. 1563-1571, 2004.

[45] Y.-L. Ji, H. Wang, P. Liu et al., "Pubertal cadmium exposure impairs testicular development and spermatogenesis via disrupting testicular testosterone synthesis in adult mice," Reproductive Toxicology, vol. 29, no. 2, pp. 176-183, 2010.

[46] D. F. Hwang and L. C. Wang, "Effect of taurine on toxicity of cadmium in rats," Toxicology, vol. 167, no. 3, pp. 173-180, 2001.

[47] N. M. Biswas, R. S. Gupta, A. Chattopadhyay, G. R. Choudhury, and M. Sarkar, "Effect of atenolol on cadmium-induced testicular toxicity in male rats," Reproductive Toxicology, vol. 15, no. 6, pp. 699-704, 2001.

[48] H. Oliveira, J. Loureiro, L. Filipe et al., "Flow cytometry evaluation of lead and cadmium effects on mouse spermatogenesis," Reproductive Toxicology, vol. 22, no. 3, pp. 529-535, 2006.

[49] E. Bonda, T. Włostowski, and A. Krasowska, "Testicular toxicity induced by dietary cadmium is associated with decreased testicular zinc and increased hepatic and renal metallothionein and zinc in the bank vole (Clethrionomys glareolus)," BioMetals, vol. 17, no. 6, pp. 615-624, 2004. 
[50] W. C. Prozialeck, J. R. Edwards, and J. M. Woods, "The vascular endothelium as a target of cadmium toxicity," Life Sciences, vol. 79, no. 16, pp. 1493-1506, 2006.

[51] C. M. Herak-Kramberger, I. Sabolić, M. Blanusa, P. J. S. Smith, D. Brown, and S. Breton, "Cadmium inhibits vacuolar $\mathrm{H}^{+}$ATPase-mediated acidification in the rat epididymis," Biology of Reproduction, vol. 63, no. 2, pp. 599-606, 2000.

[52] K. Ohtani, Y. Yanagiba, A. Ashimori et al., "Influence of injection timing on severity of cadmium-induced testicular toxicity in mice," The Journal of Toxicological Sciences, vol. 38, no. 1, pp. 145-150, 2013.

[53] I. M. El-Ashmawy and S. A. Youssef, "The antagonistic effect of chlorpromazine on cadmium toxicity," Toxicology and Applied Pharmacology, vol. 161, no. 1, pp. 34-39, 1999.

[54] R. Sarkar, K. P. Mohanakumar, and M. Chowdhury, "Effects of an organophosphate pesticide, quinalphos, on the hypothalamo-pituitary-gonadal axis in adult male rats," Journal of Reproduction and Fertility, vol. 118, no. 1, pp. 29-38, 2000.

[55] N. Akhtar, M. K. Srivastava, and R. B. Raizada, "Assessment of chlorpyrifos toxicity on certain organs in rat, Rattus norvegicus," Journal of Environmental Biology, vol. 30, no. 6, pp. 1047-1053, 2009.

[56] S. C. Joshi, R. Mathur, and N. Gulati, "Testicular toxicity of chlorpyrifos (an organophosphate pesticide) in albino rat," Toxicology and Industrial Health, vol. 23, no. 7, pp. 439-444, 2007.

[57] D. Wang, M. Kamijima, A. Okamura et al., "Evidence for diazinon-mediated inhibition of cis-permethrin metabolism and its effects on reproductive toxicity in adult male mice," Reproductive Toxicology, vol. 34, no. 4, pp. 489-497, 2012.

[58] E. Bustos-Obergón and P. González-Hormazabal, "Effect of a single dose of malathion on spermatogenesis in mice," Asian Journal of Andrology, vol. 5, no. 2, pp. 105-107, 2003.

[59] M. Uzunhisarcikli, Y. Kalender, K. Dirican, S. Kalender, A. Ogutcu, and F. Buyukkomurcu, "Acute, subacute and subchronic administration of methyl parathion-induced testicular damage in male rats and protective role of vitamins C and E," Pesticide Biochemistry and Physiology, vol. 87, no. 2, pp. 115-122, 2007.

[60] P. Alahyary, M. I. Poor, F. F. Azarbaijani, and V. Nejati, "The potential toxicity of diazinon on physiological factors in male rat," Pakistan Journal of Biological Sciences, vol. 11, no. 1, pp. 127130, 2008 .

[61] K. Narayana, "Methyl parathion induces the formation of symplasts by round spermatid fusion and alters the biochemical parameters in the testis," Morphologie, vol. 91, no. 294, pp. 173179, 2007.

[62] A. Okamura, M. Kamijima, K. Ohtani et al., "Broken sperm, cytoplasmic droplets and reduced sperm motility are principal markers of decreased sperm quality due to organophosphorus pesticides in rats," Journal of Occupational Health, vol. 51, no. 6, pp. 478-487, 2009.

[63] N. Choudhary, R. Goyal, and S. C. Joshi, "Effect of malathion on reproductive system of male rats," Journal of Environmental Biology, vol. 29, no. 2, pp. 259-262, 2008.

[64] N. Prashanthi, K. Narayana, A. Nayanatara, H. H. C. Kumar, K. L. Bairy, and U. J. D'Souza, "The reproductive toxicity of organophosphate pesticide 0, 0-dimethyl 0-4-nitrophenyl phosphorothioate (methyl parathion) in the male rat," Folia Morphologica, vol. 65, no. 4, pp. 309-321, 2006.
[65] A. A. Fouad, H. A. Qureshi, A. I. Al-Sultan, M. T. Yacoubi, and A. A. Ali, "Protective effect of hemin against cadmium-induced testicular damage in rats," Toxicology, vol. 257, no. 3, pp. 153-160, 2009.

[66] M. Işcan, A. O. Ada, T. Çoban, N. Kapucuoğlu, A. Aydin, and A. Işimer, "Combined effects of cadmium and nickel on testicular xenobiotic metabolizing enzymes in rats," Biological Trace Element Research, vol. 89, no. 2, pp. 177-190, 2002.

[67] H. Chovancová, R. Omelka, I. Boboňová, G. Formicki, R. Toman, and M. Martiniaková, "Bone adaptation to simultaneous cadmium and diazinon toxicity in adult male rats," Potravinarstvo, vol. 8, no. 1, pp. 107-113, 2014.

[68] J. Jebali, M. Banni, H. Guerbej, E. A. Almeida, A. Bannaoui, and H. Boussetta, "Effects of malathion and cadmium on acetylcholinesterase activity and metallothionein levels in the fish Seriola dumerilli," Fish Physiology and Biochemistry, vol. 32, no. 1, pp. 93-98, 2006.

[69] J. F. Gonçalves, F. T. Nicoloso, P. da Costa et al., "Behavior and brain enzymatic changes after long-term intoxication with cadmium salt or contaminated potatoes," Food and Chemical Toxicology, vol. 50, no. 10, pp. 3709-3718, 2012.

[70] H. Carageorgiou, V. Tzotzes, C. Pantos, C. Mourouzis, A. Zarros, and S. Tsakiris, "In vivo and in vitro effects of cadmium on adult rat brain total antioxidant status, acetylcholinesterase, $\left(\mathrm{Na}^{+}, \mathrm{K}^{+}\right)$-ATPase and $\mathrm{Mg}^{2+}$-ATPase activities: protection by Lcysteine," Basic \& Clinical Pharmacology \& Toxicology, vol. 94, no. 3, pp. 112-118, 2004

[71] A. W. Olmstead and G. A. LeBlanc, "Toxicity assessment of environmentally relevant pollutant mixtures using a heuristic model," Integrated Environmental Assessment and Management, vol. 1, no. 2, pp. 114-122, 2005.

[72] Y. Yu, A.-M. Yang, J.-H. Zhang, S.-K. Hu, and H. Yan, "Synergistic effect of dichlorvos, dimethoate and malathion mixture on reproduction toxicity in male mice," Chinese Journal of Preventive Medicine, vol. 45, no. 9, pp. 810-814, 2011.

[73] J. S. Thakur, S. Prinja, D. Singh et al., "Adverse reproductive and child health outcomes among people living near highly toxic waste water drains in Punjab, India," Journal of Epidemiology \& Community Health, vol. 64, no. 2, pp. 148-154, 2010. 

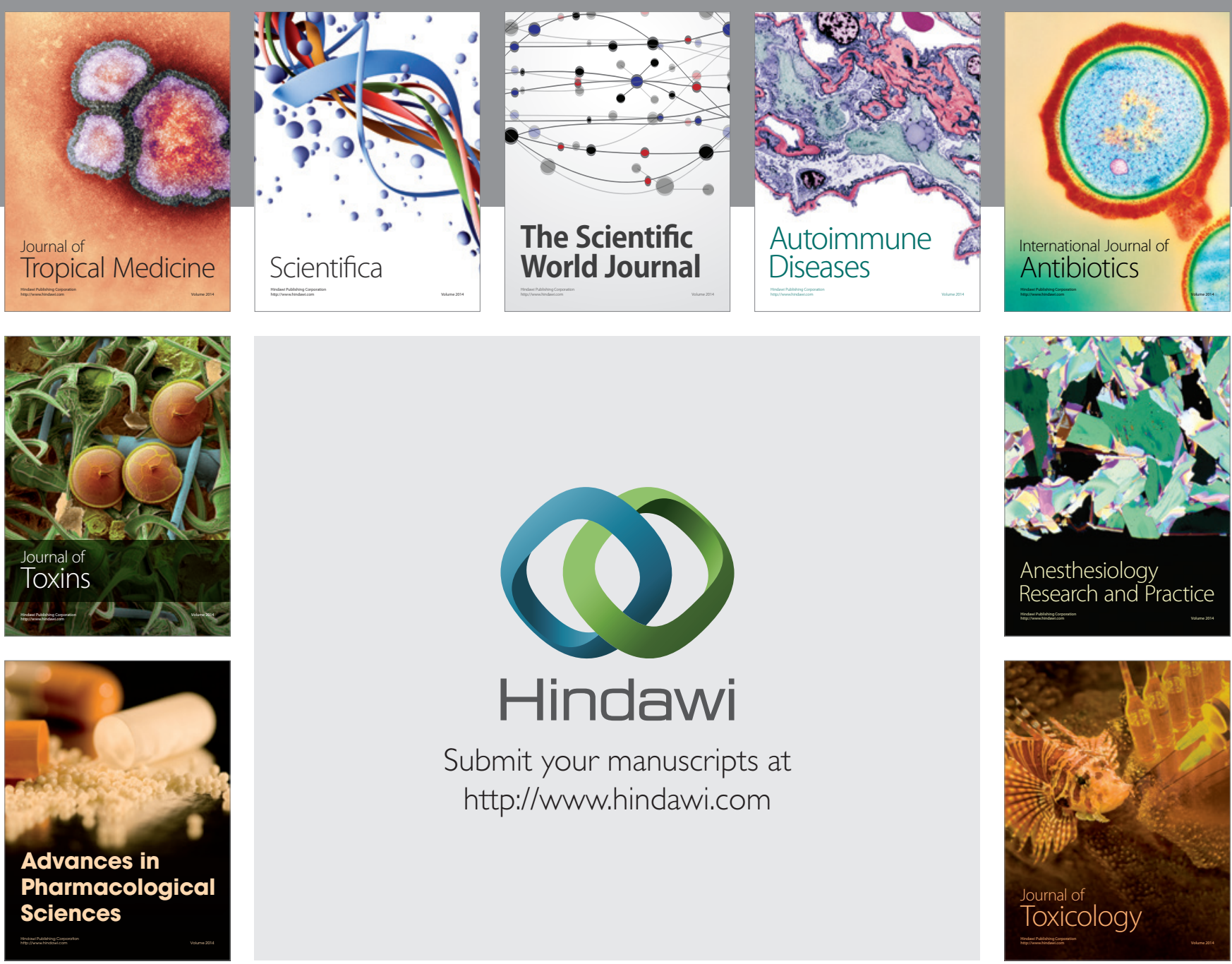

\section{Hindawi}

Submit your manuscripts at

http://www.hindawi.com
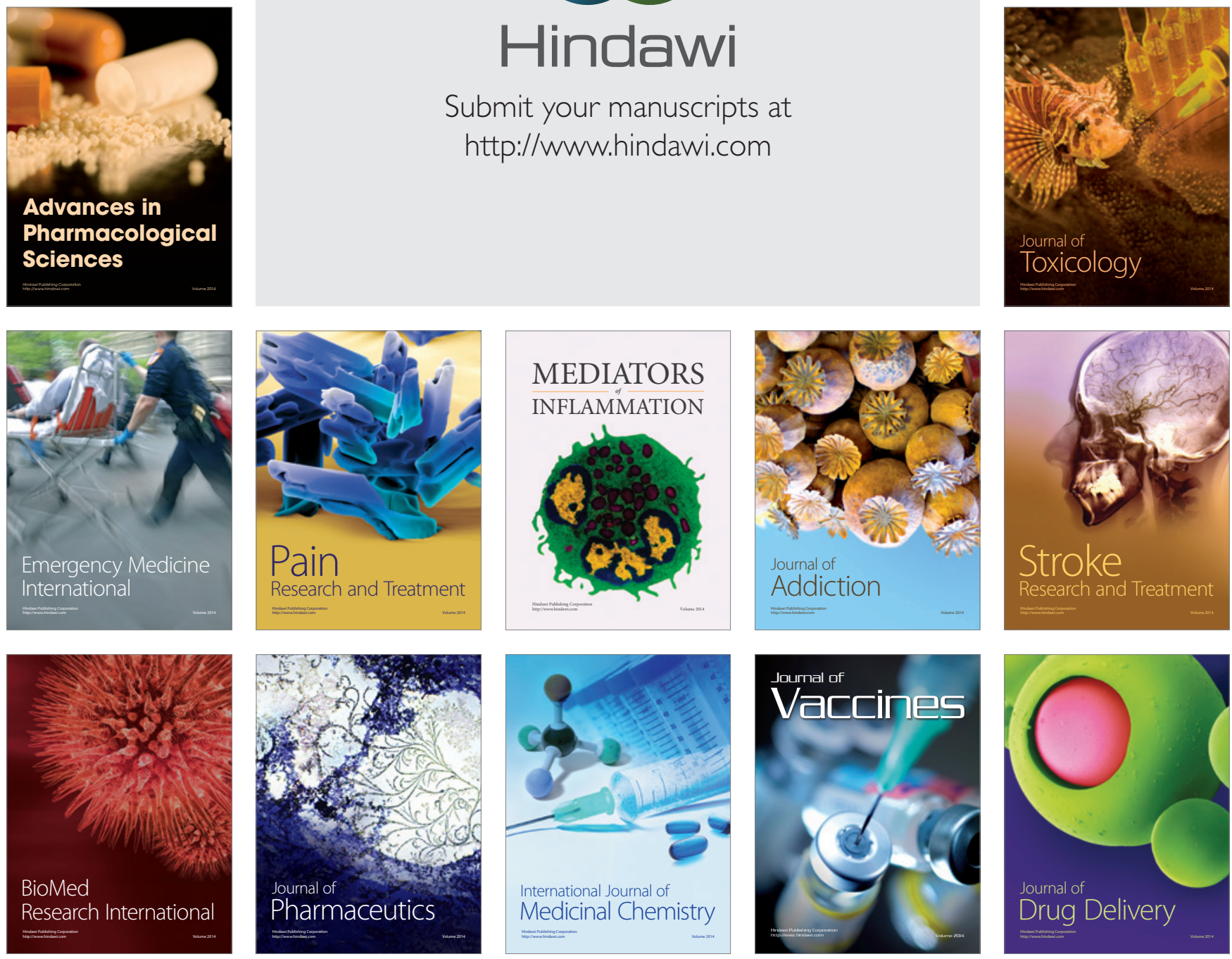